\title{
EDUCAÇÃO PENITENCIÁRIA NO ESTADO DO AMAPÁ: O PAPEL SOCIAL DA ESCOLA ESTADUAL SÃO JOSÉ ${ }^{1}$
}

\author{
Lisete Clemente \\ Roma Reis de Almeida \\ Leila Nazaré dos Santos Passos
}

\section{INTRODUÇÃO}

O trabalho discute o papel social da Escola Estadual São José - EESJ à população carcerária e foi desenvolvido por Clemente, Almeida e Passos (2008), como pesquisa de especialização, orientado pela professora Nilceia Margareth da Silva Figueiredo Chermont.

A EESJ atua com oferta de cursos aos presos condenados e provisórios do Instituto de Administração Penitenciária do Estado do Amapá - IAPEN. A partir de 2004, esta instituição de ensino tornou-se autônoma do Centro de Estudos Supletivos Emílio Médici - CESEM e de sua gestão escolar, pois desde 1996, o corpo docente responsável pelo ensino dentro da penitenciária, era de responsabilidade dos mesmos professores desse Centro de Estudos.

O texto foi estruturado em três partes: Educação em prisões no Brasil e integração social, A Estrutura Física e Organizacional da EESJ no ano de 2008 e seu trabalho no período em que Lisete Clemente foi gestora da escola, tendo como questão norteadora: Como tem atuado a escola para colaborar com o processo de integração social dos presos condenados e provisórios, considerando que eles vivenciam a prisonização no encarceramento?

O referencial teórico deste estudo dialoga com os estudos de Foucault (1977; 2005), Thompson (1976), Marcão (2005), Nunes (2005), Almeida (2006), Abreu (2008), Vasquez (2008), documentos e fotografias da EESJ, entre outras referências. Além disso, em 2007, realizamos entrevista com a professora Eliane Leal Vasquez, que fazia parte do corpo docente da EESJ.

As orientações para o planejamento da entrevista, basearam-se no livro Manual de História Oral de Alberti (2005). A entrevistada assinou o Termo de Consentimento e Livre Esclarecido (TCLE) para uso da citação da entrevista em trabalho acadêmico.

${ }^{1}$ DOI: $10.29388 / 978-65-86678-21-5-f .37-56$. 


\section{EDUCAÇÃO EM PRISÕES NO BRASIL E INTEGRAÇÃO SOCIAL}

De acordo com Vasquez (2007b), a respeito do debate da educação nas prisões no Brasil é possível dizer:

A educação nas prisões é um tema ainda esquecido pela historiografia da educação brasileira, excetuando-se pelas poucas pesquisas em níveis de mestrado e doutorado existentes ou em andamento e disponíveis nas estantes das bibliotecas de algumas instituições de ensino superior. Contudo a educação na prisão é um direito do apenado e interno, regulamentada atualmente pela Lei de Execução Penal (Lei nº 7210/1984), tendo como finalidade regimentar em âmbito nacional o funcionamento e a efetivação das disposições de sentença ou decisão criminal, e proporcionar condições para a harmônica integração social do condenado e interno (VASQUEZ, 2007b, p. 1).

Desde a sanção da Lei de Execução Penal - LEP pelo presidente João Batista de Oliveira Figueiredo, a referida lei alterou as Normas Gerais do Regime Penitenciário do Brasil - NGRP, além das atribuições da inspetoria-geral penitenciária, decretada pelo presidente Juscelino Kubitschek de Oliveira e que foi assinada por Nereu de Oliveira Ramos e João de Oliveira Castro Viana Júnior (BRASIL, 1984; 1957).

Quando passou a vigorar a LEP, ocorreu a reformulação da assistência e do tratamento penitenciário ao homem e mulher que praticaram crimes. Em consequência, os profissionais que trabalham nas prisões, desde 1984, passaram a desenvolver suas atividades laborais, tendo como foco promover a integração social entre as pessoas presas, profissionais da educação e os demais membros da sociedade amapaense.

Nesse cenário, a LEP reafirmou o direito à educação ao preso e interno no Brasil, com a determinação do Capítulo II - Da Assistência/Seção V - Da Assistência Educacional (GOMES, 2006), ou seja, a obrigatoriedade das Unidades Federadas garantirem a assistência educacional dentro das prisões, com objetivo de assistir à população carcerária, mas apenas para curso de ensino fundamental e formação profissional.

Entretanto, existe um paradoxo social para efetivação com qualidade da assistência educacional à população carcerária. É o fato que o espaço em que estão as escolas dentro das prisões, prevalece o controle dos corpos, a vigília dos comportamentos e punição a alma das pessoas que cometeram crimes, como nos leva a refletir Foucault $(1977,2005)$. 
Estas características predominam na "prisão-aparelho"2 a partir do século XIX, quando passou a funcionar com base nos princípios da "correção, classificação, modulação da pena, trabalho como obrigação e direito, educação penitenciária, controle técnico da detenção que norteiam as técnicas penitenciárias e das instituições anexas" (FOUCAULT, 1977, p. 237-238).

Neste caso, desde o século XIX, a escola, o hospital e outras instituições passaram a constituir a estrutura organizacional das prisões, tempo em que se iniciou a entrada nas prisões dos capelães, educadores, psiquiatras, guardas, psicólogos, funcionários da administração penitenciária (FOUCAULT, 1977), com o fim de aplicar as técnicas penitenciárias na execução da pena privativa de liberdade.

Assim, a prática quase total do controle, vigília e punição aos presos e internos, quando descumprindo as normas das prisões, é parte dos fatores que se contrapõem ao funcionamento das escolas dentro das prisões, pois o cotidiano carcerário preza pela segurança e controle do movimento dos apenados, fora de seus pavilhões ou suas celas.

Uma consequência é o atraso na realização dos serviços educacionais, em decorrência da demora de liberação dos apenados de suas celas para serem encaminhados à escola, ou seja, o que sobressai no ambiente carcerário não é educar. Mas trabalhar, vigiar e punir como instrumento de coerção mental (neste caso no pavilhão da punição) e ocupação laboral para baixo custo.

Com relação a alguns dos problemas da crise na execução penal no Brasil, Marcão (2005) comenta:

Nem é preciso dizer muito. Todos sabem o que ocorre na realidade. Estabelecimentos prisionais em número reduzido, que não atende à demanda. Celas superlotadas e espaços físicos exíguos até mesmo para outras necessidades básicas e muitas vezes fisiológicas. Acomodações, em geral, precárias, mercê da crescente criminalidade, cujos vários fatores já apontamos em outras ocasiões, só superados pelo descaso do Poder Executivo na seara de que cuidamos (MARCÃO, 2005, p. 4).

Por outro lado, Marcão (2005) explica sobre as relações da CF e da LEP, com outras regulamentações nacionais e internacionais, que tratam da obrigatoriedade da educação ao preso e interno ao nível de ensino fundamental:

${ }^{2}$ FOUCAULT, M. Vigiar e Punir: Nascimento da prisão, 1977, p. 209. 
Estão em harmonia com as Regras Mínimas da ONU para o Tratamento de Reclusos, adotadas em 31 de agosto de 1955, pelo Primeiro Congres so das Nações Unidas para a Prevenção do Crime e o Tratamento dos Delinqüentes; com as Regras Mínimas para o Tratamento do Preso no Brasil - Resolução n 14, do Conselho Nacional de Política Criminal e Penitenciária (CNPCP), de 11 de novembro de 1994 (DOU de 02.12.94), e com a Declaração Universal dos Direitos Humanos, estando expresso nesta que: Todo homem tem direito à instrução. A instrução será gratuita, pelo menos nos graus elementares e fundamentais [...] (MARCÃO, 2005, p. 3).

Em contrapartida, Vasquez (2006b) lembra que :

[...] mesmo com estas determinações da legislação penal quanto à Educação Penitenciária, seu reconhecimento no Brasil ainda está num estado de invisibilidade na própria Lei de Diretrizes e Bases da Educação Lei n⿳9394/96, considerando que não se tem [...], nenhuma menção quanto às especificidades inerentes as orientações para a Educação de Adultos na Prisão (VASQUEZ, 2006b, p. 8).

É por isso que no Brasil, os adultos presos ou os egressos do sistema penitenciário têm acesso à educação escolar pela modalidade da Educação de Jovens e Adultos (EJA), com os cursos ofertados em escolas da rede pública de ensino, localizadas em áreas urbanas ou rurais e também nas escolas localizadas nas prisões.

Contudo, a partir da execução do Projeto Educar para a Liberdade, sob coordenação da UNESCO no Brasil e da realização do I e II Seminário Nacional de Educação nas Prisões, as primeiras propostas para implantação das diretrizes que orientassem em âmbito nacional a qualidade da educação no cárcere, começaram a ser formuladas pelas instituições envolvidas com os problemas penitenciários (UNESCO, 2006, 2007; NUNES, 2007).

Das poucas informações sobre a realidade da educação nas prisões, como uma das formas de integração social da pessoa presa ou custodiada, o Relatório do Tribunal de Contas da União - TCU, citado por Nunes (2005), chama a atenção para os seguintes fatos:

A Lei de Execução Penal virou letra morta. Contém normas de prevenção ao crime e de recuperação ao criminoso, absolutamente desprezadas, sem se contar que os direitos dos presos são desrespeitados. Os nossos estabelecimentos prisionais não foram planejados para desenvolver ativi- 
dades de educação, profissionalização e trabalho. Faltam salas de aulas e oficinas, por exemplo. Há, no país, 46,5 mil agentes penitenciários: somente cinco mil deles atuam em atividades que proporcionam a ressocialização do criminoso, os demais se dedicam à segurança (NUNES, 2005, p. 9-10).

Ressaltam ainda os auditores que elaboram o respectivo relatório que:

[...] das dezoito penitenciárias visitadas em nove Estados, cento e oito presos foram entrevistados: $77 \%$ deles não estudam; onde há ensino básico, ele é precário e descontinuado. Em São Paulo, com quase metade da população carcerária nacional e o Estado mais rico da Federação, somente $17 \%$ dos presos freqüentam a escola. Em Estados como Espírito Santo, Acre, Rondônia, Goiás, Amazonas e Pará, só 7\% dos presos estudam [...] (NUNES, 2005, p. 9-10).

Os dados estatísticos apresentados por Nunes (2005) não contemplam informações sobre a assistência educacional no Instituto de Administração Penitenciária do Amapá - IAPEN. Quanto às conclusões do Relatório do TCU, analisado pelo autor, pode-se inferir que são poucas as experiências desenvolvidas nas prisões do Brasil que efetivamente colaboram com a recuperação do criminoso, mas muitas são as ações no sentido de fazê-lo retornar ao crime, conforme o TCU (apud NUNES, 2005, p. 10).

Partindo da conclusão que na pesquisa realizada pelos auditores do TCU não se mencionou o caso do sistema penitenciário amapaense, então, de que forma tem atuado a escola localizada no IAPEN para colaborar com o processo de integração social dos presos condenados e provisórios, considerando que a população carcerária enfrenta a prisonização?

É importante dizer que a prisonização é “a adoção pelo preso ou profissional que com ele atua em maior ou menor grau do modo de pensar, costumes ou hábitos próprios da cultura prisional, uma espécie de deslize para dentro dos padrões existentes na comunidade prisional", de acordo com Clemmer (apud THOMPSON, 1976, p. 52-53).

Vasquez (2008) destaca que a cultura latente nas instituições penais é a cultura prisional, correspondente ao desenvolvimento de hábitos, linguagens, comportamentos e atitudes para satisfazer as necessidades da sociedade cativa, conceito que foi apresentado por Clemmer (1960) no livro The Prison Community.

Com relação à cultura prisional, há de se considerar que existem alguns fatores que podem variar de acordo com a intensidade em que a pessoa que se 
permitiu ser prisonizada, dentre eles: a aceitação de um papel inferior no grupo; desenvolvimento de hábitos de comer, dormir, vestir, trabalhar, dormir e adoção de linguagem local e outros (CLEMMER, 1960).

Nesse sentido, cabe destacar que o corpo discente das escolas localizadas nas prisões, no seu cotidiano, adapta-se à cultura prisional. Esta realidade provavelmente contribui para o baixo índice de participação nas atividades educativas, uma vez que, os interesses da população carcerária são de caráter coletivo em detrimento de interesses particulares dos presos novatos ou até mesmo dos presos antigos.

$\mathrm{Na}$ prisão, as decisões são tomadas em benefício de grupos dominantes, formados por alguns presos e funcionários da instituição penitenciária, envolvendo o poder prisional e o poder institucional. Assim, enquanto o corpo docente ensina conhecimentos e comportamentos que fazem parte da cultura escolar, por outro lado, a população carcerária participa ativamente da cultura prisional (VASQUEZ, 2008), caracterizada por outros conhecimentos, atitudes, linguagens e práticas que diferem do que é promovida dentro do espaço escolar pelos professores no ambiente carcerário.

\subsection{Prisões e escolas envolvidas com a educação de adultos presos no Amapá}

Pouco se tem estudado sobre a história das prisões no Amapá e sobre as instituições envolvidas com a educação de adultos presos no norte do Brasil.

Por isso, vale ressaltar algumas pesquisas que foram realizadas de 1999 até 2008: A Educação no Complexo Penitenciário do Estado do Amapá; Sistema Prisional. A Recuperação do Preso: realidade ou utopia?; Educação entre Grades; Prisão, Penitenciária ou Instituto Penal: Um olhar Histórico sobre sistema carcerário do Estado do Amapá e suas transformações (1995-2005); Sociedade Cativa. Entre cultura escolar e cultura prisional: Uma incursão pela ciência penitenciária; Educação entre Grades: Um estudo sobre a educação penitenciária no Amapá (DIAS et al, 1999; SILVA, OLIVEIRA, NOBREGA, 2001; BRAGA et al, 2002; ALMEIDA, 2006; VASQUEZ, 2008; ABREU, 2008).

As pesquisas de Dias et al (1999), Silva, Oliveira e Nobrega (2001), Braga et al (2002), Almeida (2006), Vasquez (2008) e Abreu (2008) foram desenvolvidas, respectivamente, na Universidade Federal do Amapá - UNIFAP, Faculdade de Macapá - FAMA e Pontifícia Universidade Católica de São Paulo PUC/SP e Universidade Federal de São Carlos - UFSCAR. 
Os seus resultados contribuíram para a construção de parte da História das Prisões do Amapá e para a História da Educação Penitenciária. Esses estudos reuniram informações sobre as prisões amapaenses, além de evidenciar as escolas que atuaram com ofertas de cursos de ensino médio e fundamental aos adultos presos no período de 1996 até 2008, como o anexo do Centro de Ensino Supletivo Emílio Médici - CESEM, que passou a chamar-se de Centro de Educação de Jovens e Adultos - CEJAEM, e por último, a Escola Estadual São José - EESJ.

Vasquez (2008) apresentou no anexo de sua pesquisa um resumo da construção e transformação das prisões no Território Federal e Estado do Amapá e mudanças que ocorreram, quanto às edificações e melhorias em prédios das prisões e das escolas, o que a autora destacou na $2^{a}$ e $3^{a}$ colunas do Quadro I:

Quadro I - Construção e transformação das prisões no Amapá

\begin{tabular}{|c|c|c|}
\hline $\begin{array}{l}\text { Administração } \\
\text { do Governo }\end{array}$ & $\begin{array}{c}\text { Prédios da Arquitetura } \\
\text { Penitenciária }\end{array}$ & $\begin{array}{c}\text { Construção/Implantação } \\
\text { Melhorias/Mudanças }\end{array}$ \\
\hline $\begin{array}{c}\text { Janary Gentil Nunes } \\
1944-1956\end{array}$ & $\begin{array}{l}\text { Prédios da Cadeia de Ma- } \\
\text { capá e provavelmente a } \\
\text { Colônia de São Pedro ou } \\
\text { Colônia Penal do Beirol. }\end{array}$ & $\begin{array}{l}\text { Edificação dos primeiros pré- } \\
\text { dios da segurança pública e } \\
\text { do sistema penitenciário do } \\
\text { território do Amapá. }\end{array}$ \\
\hline $\begin{array}{c}\text { Anníbal Barcelos } \\
\text { 1979-1985 }\end{array}$ & $\begin{array}{l}\text { Prédios destinados ao sis- } \\
\text { tema prisional polivalen- } \\
\text { te, prédios da parte agrí- } \\
\text { cola da penitenciária, pré- } \\
\text { dios do corpo da guarda, } \\
\text { construção do prédio da } \\
\text { escola na Colônia de São } \\
\text { Pedro. }\end{array}$ & $\begin{array}{l}\text { Ampliação da Colônia Agrí- } \\
\text { cola de São Pedro, com cons- } \\
\text { trução de uma escola na mes- } \\
\text { ma. Além de edificação de } \\
\text { novos prédios do sistema pri- } \\
\text { sional polivalente e investi- } \\
\text { mento na rede elétrica/água } \\
\text { da Penitenciária Agrícola do } \\
\text { Amapá. }\end{array}$ \\
\hline $\begin{array}{l}\text { Jorge Nova da Costa } \\
1985-1986 / 1986-1990\end{array}$ & $\begin{array}{l}\text { Pavilhão da cozinha e re- } \\
\text { feitório da Penitenciária } \\
\text { Agrícola do Amapá. Esta } \\
\text { penitenciária posterior- } \\
\text { mente passa a denomi- } \\
\text { nar-se Colônia Penal } \\
\text { Agrícola e Industrial do } \\
\text { Amapá e construção do }\end{array}$ & $\begin{array}{l}\text { Além das reformas em pré- } \\
\text { dios da Penitenciária Agrícola } \\
\text { do Amapá, foram construídos } \\
\text { também mais três pavilhões, } \\
\text { um pavilhão para os presos e } \\
\text { demais para a enfermaria e } \\
\text { matadouro da penitenciária } \\
\text { do estado e construção da }\end{array}$ \\
\hline
\end{tabular}




\begin{tabular}{|c|c|c|}
\hline & $\begin{array}{l}\text { prédio destinado para a } \\
\text { escola. }\end{array}$ & $\begin{array}{l}\text { primeira parte do prédio es- } \\
\text { colar. }\end{array}$ \\
\hline $\begin{array}{c}\text { Anníbal Barcelos } \\
\text { 1991-1994 }\end{array}$ & $\begin{array}{l}\text { Colônia Penal Agrícola e } \\
\text { Industrial do Amapá } \\
\text { ocorreu a reconstrução } \\
\text { do prédio da escola, por } \\
\text { motivo de ter sido incen- } \\
\text { diada durante rebelião } \\
\text { dos presos. }\end{array}$ & $\begin{array}{l}\text { Investimento na estrutura físi- } \\
\text { ca e aparato policial, com au- } \\
\text { mento de número de viaturas } \\
\text { policiais e ampliação do qua- } \\
\text { dro funcional referente à se- } \\
\text { gurança pública e reconstru- } \\
\text { ção do prédio escolar. }\end{array}$ \\
\hline $\begin{array}{l}\text { João Alberto Cabiberibe } \\
\text { 1995-2002 }\end{array}$ & $\begin{array}{l}\text { Complexo Penitenciário } \\
\text { do Amapá e Unidade Es- } \\
\text { colar/Centro de Estudos } \\
\text { Supletivo Emílio Médici. }\end{array}$ & $\begin{array}{l}\text { Modificação na nomenclatura } \\
\text { da Colônia Penal do governo } \\
\text { anterior para Complexo Peni- } \\
\text { tenciário do Amapá. Além da } \\
\text { ampliação do prédio escolar } \\
\text { que a partir de } 1996 \text {, passou a } \\
\text { ser um anexo do Centro de } \\
\text { Estudos Supletivos Emílio } \\
\text { Médidi. }\end{array}$ \\
\hline $\begin{array}{l}\text { Maria Dalva de Souza } \\
\text { Figueiredo e Antônio } \\
\text { Waldez da Silva Góes } \\
\text { 2002/2003-Atual }\end{array}$ & $\begin{array}{l}\text { Instituto Penitenciário do } \\
\text { Estado do Amapá e Es- } \\
\text { cola Estadual São José. }\end{array}$ & $\begin{array}{l}\text { Reformulação no estatuto pe- } \\
\text { nitenciário do Amapá e modi- } \\
\text { ficação da nomenclatura do } \\
\text { Complexo Penitenciário para } \\
\text { Instituto de Administração } \\
\text { Penitenciária do Amapá. } \\
\text { Além de modificação do } \\
\text { nome da unidade escolar para } \\
\text { Escola Estadual São José. }\end{array}$ \\
\hline
\end{tabular}

Fonte: (VASQUEZ, 2008, p. 147).

O Quadro I informa os nomes de prisões do Território Federal e Estado do Amapá, ressaltando a construção de prédios em que as pessoas presas cumpriam suas sentenças criminais ou que foram custodiadas provisoriamente. Além de mencionar sobre a construção e reconstrução dos prédios das escolas no sistema penitenciário, em um período da História do Brasil e do Amapá, marcado pela transição do regime militar à democratização da política brasileira. 


\section{A ESTRUTURA FÍSICA E ORGANIZACIONAL DA EESJ}

De acordo com o Estatuto Penitenciário do Estado do Amapá (AMAPÁ, 2002), o sistema penitenciário é formado por sete órgãos, distribuídos entre "estabelecimentos penitenciários; presidiários; agrícola, industriais ou mistos; médicos-penais; centro de observação criminológica e de triagem; casa do albergado; patronato e pró-egresso".

É interessante perceber que a presença de escolas não está citada na constituição dos órgãos que compõem o sistema penitenciário amapaense. Assim, a assistência educacional como forma de integração social à pessoa presa ou custodiada nas prisões, efetivou-se no Amapá pelo trabalho desenvolvido pelos professores da Secretaria de Estado da Educação.

A assistência educacional no sistema penitenciário amapaense passou por distintas fases, no período de 1975 até 2007, como esclarece o trecho da entrevista:

Infelizmente ainda não temos registrada a história da escola em que trabalhamos. Dessa forma, as informações que temos a esse respeito são decorrentes de conversas com ex-professores e diretores que desempenharam suas funções docentes e administrativas na escola localizada no IAPEN, hoje chamada de Escola Estadual São José - EESJ. Com base em dados de fonte oral sobre o tema, é possível dizer que se fossemos falar sobre a História da Educação Penitenciária no Amapá, teríamos que recompor as informações quanto a três fases distintas. A primeira em que a assistência educacional era garantida por meio da execução do Projeto Minerva, ou seja, o tempo do ensino via Rádio, sob coordenação direta da Secretaria de Educação e Cultura do Território do Amapá, desde 1975, além de outros programas educacionais, como o Projeto João da Silva e Programa de Classes Integradas. Em seguida, ocorreu a implantação do Ensino Personalizado, isto é, Ensino por Módulos, contemplando as disciplinas de língua portuguesa, geografia, matemática, ciências, história e matemática sob responsabilidade dos professores do Centro de Estudos Supletivos Emílio Médici a partir de 1996. E por último, a oferta de Cursos da Educação de Jovens e Adultos na Educação Penitenciária

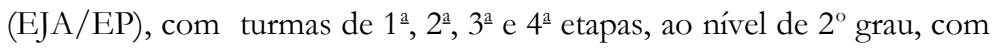
docência de todas as disciplinas da Educação de Jovens e Adultos - EJA. Quanto ao primeiro grau, esta fase ocorreu desde 2003 e com relação as turmas de $1^{\underline{a}}$ e $2^{\underline{a}}$ etapas, em nível de $2^{\circ}$ grau, iniciaram a partir de 2006. Eu fiz parte do corpo docente desde 1999 e ensinei Matemática na época do Ensino por Módulos e também nas turmas regulares dos cursos da 
EJA/EP. É importante lembrar que ainda não é obrigatório que as Unidades Federadas garantam a oferta de curso de ensino médio dentro das prisões. No Amapá, a gestora da EESJ decidiu ofertar o curso de ensino médio à população carcerária, pois o número de alunos-presos que ficavam na ociosidade após a conclusão do ensino de $1^{\circ}$ grau era elevado e os professores da escola apoiaram a proposta da gestora Lisete Clemente (VASQUEZ, 2007c, p. 1).

Estas informações revelam parte da história da educação penitenciária no Amapá. A Secretaria do Território Federal e do Estado da Educação, seguindo os programas e os projetos do Governo Federal, tem proporcionado a formação escolar à população carcerária através dos serviços prestados pelos profissionais da educação, vinculados a esta secretaria e que se deslocam para trabalhar no sistema penitenciário.

Com base nesses dados apresentados, depreende-se que é inegável o papel social da Escola Estadual São José - EESJ (Figura 1), principalmente, por funcionar no ambiente de carcerário. Mesmo diante da dificuldade que se insere a escolarização dentro do cárcere, professores trabalham com a oferta de cursos pela modalidade Educação de Jovens e Adultos na Educação Penitenciária.

Figura 1 - EESJ entre a quadra esportiva e o pavilhão da cozinha

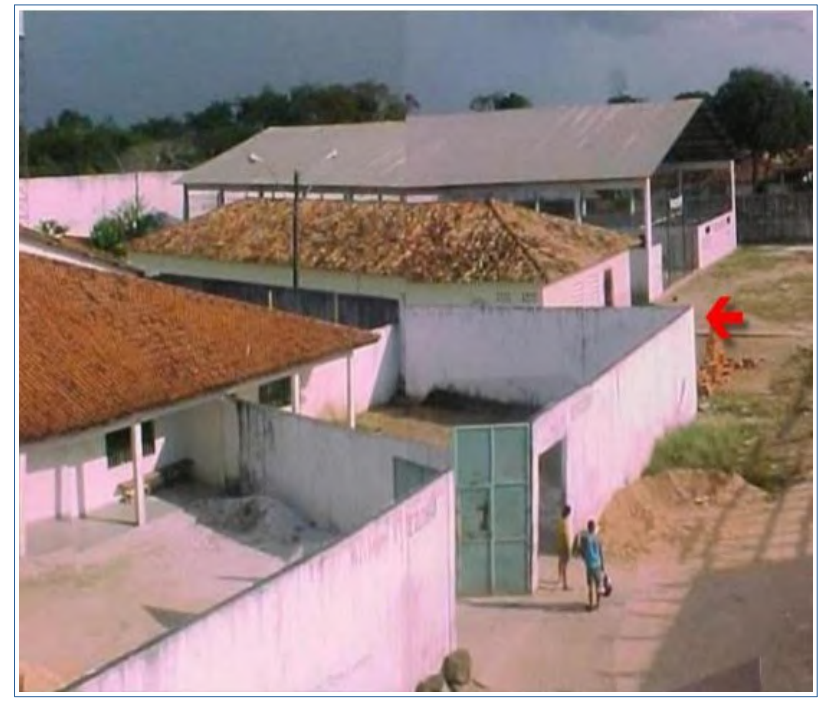

Fonte: (OLIVEIRA, 2007, p. 3). 
A Figura 1 exemplifica parte de algumas das dificuldades que enfrentam o corpo docente e técnico-administrativo para o exercício de suas funções na escola, que se localizava entre a Quadra Esportiva e o Pavilhão da Cozinha, na área interna do "cadeião", ou seja, no espaço destinado aos pavilhões masculinos, onde ficam os presos condenados e provisórios.

Em 2008, a estrutura física e organizacional da EESJ era composta por 5 salas de aulas, 1 cozinha, 1 sala destinada à Direção Escolar, 1 biblioteca, 1 sala de material, 1 sala da Unidade de Assistência Escolar e Profissionalizante UNAEP e 3 banheiros. Vale ressaltar que, em 2007, a escola não tinha (sala para a secretaria escolar, sala de professores e sala para aulas práticas para disciplina de Educação Física).

Também é importante destacar a atuação do corpo discente da EESJ em atividades educativas e de inclusão social, que ocorreram no período de 2004 a 2007, sob coordenação da Direção Escolar e Coordenação Pedagógica, cujo planejamento e execução foi realizado pelo corpo docente e colaboradores, o que abordaremos na próxima seção do texto.

\subsection{Projetos, reestruturação da biblioteca na EESJ, Exame de Massa e Exame Nacional do Ensino Médio no IAPEN}

Os presos condenados e provisórios que frequentaram cursos ofertados em turmas da Educação de Jovens e Adultos na Educação Penitenciária, na capital do Estado do Amapá, no período de 2005 a 2007, receberam a remição de pena pelo estudo, em cumprimento à Portaria TJAP no 009/05-VEP (EESJ, 2005).

A matrícula escolar, nesse período era realizada pelo adulto preso, geralmente, no mês de janeiro, na EESJ, momento em que era necessário ter o seu nome agendado no Boletim Interno do IAPEN para ser escoltado do seu pavilhão à escola. A Coordenação Pedagógica durante o período de matrícula priorizava no ato de inscrição, primeiramente, quem já era estudante da EESJ, em seguida, eram preenchidas as demais vagas dos Cursos, de acordo com a lista das pessoas presas que estavam autorizadas a deslocar-se das suas celas à escola, com a finalidade de solicitar a sua matrícula, devidamente selecionados pela Coordenadoria de Tratamento Penal - COTRAP, um dos órgãos do IAPEN.

Com a implantação da turma piloto do Curso do Ensino Médio a partir de 2006, foi possível a participação de vinte e um estudantes-presos no Concurso Vestibular (2008) da Universidade Federal do Amapá, sendo aprovados na primeira fase para os cursos de Secretariado Executivo e Enfermagem, respecti- 
vamente, Rogério Ferreira da Silva, Joaquim Malison Pinheiro de Azevedo e Reney Ferreira Macedo (UNIFAP, 2008, p. 2-3). Somente, Rogério Ferreira da Silva foi aprovado na fase final do Concurso Vestibular. Entretanto, ele não iniciou os seus estudos na educação superior, pois não foi autorizado a frequentar a universidade pelo juiz da VEP/TJAP.

No período de 2004 a 2007, alguns dos projetos educacionais que foram executados pelo corpo docente da EESJ, como (Ao Encontro da Escola Cidadã: Resultados dos Processos de Ensinar e Aprender na Escola Estadual São José; Teia da Desprisonização; Independência do Brasil; Semana do Folclore da Escola Estadual São José; Arraiá de São José; Mãe, Família e Escola; A Páscoa; Informação sobre as Doenças Sexualmente Transmissíveis como forma de transformação (Figura 2); Festa da Família, com apresentação da expressão corporal "O conceito de família a partir do olhar do aluno-preso" (EESJ, 20042007; VASQUEZ, 2007a; 2007b).

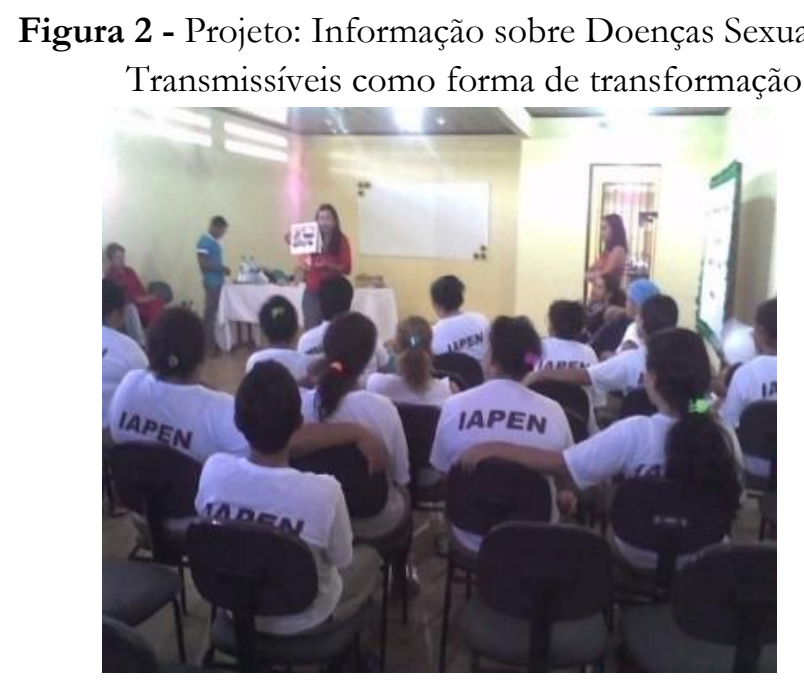

Fonte: (EESJ, 2007).

O corpo docente visando contribuir com o repensar de atitudes, valores e relação interpessoal entre a comunidade prisional e profissionais da educação, passou a desenvolver projetos com foco na parte diversificada do currículo escolar da Educação de Jovens e Adultos na Educação Penitenciária, o que envolveu todas as disciplinas dos cursos ofertados. Esses projetos educacionais tinham como objetivo, fomentar a prática de diferentes formas do ser humano se expressar e aprender na escola inserida dentro da prisão. 


\subsection{Reestruturação da biblioteca}

Por volta de 2003, foi reestruturado um espaço para a biblioteca da EESJ, com o fim de disponibilizar o acesso a seu acervo para estudos, leitura e/ou empréstimos de livros às pessoas presas. A organização dos livros da biblioteca foi realizada manualmente, pois a escola não tinha computador.

Quanto à aquisição desses livros, Vasquez (2007d, p. 9) observa que na maioria das vezes:

[...] são obtidos por meio de campanhas de doações organizadas pelos poucos membros da sociedade civil, a exemplo de professores, educadores sociais penitenciários e profissionais de outras áreas que se sensibilizam e cooperam ativamente com a educação prisional ou envio de acervo bibliográfico pelo Ministério da Educação/Secretaria de Estado da Educação.

Quanto ao atendimento aos usuários da biblioteca da EESJ (Figura 3), no período de 2004 a 2005, as responsáveis pela biblioteca, eram Carla Marcela Trindade de Assis e Maria Cleane de Moraes Gomes, duas educadoras sociais penitenciárias, que também eram servidoras públicas do Governo do Estado do Amapá.

Já a partir de 2006, os serviços da biblioteca foram suspensos, por falta de lotação de servidor. Por isso, a biblioteca passou a ficar aberta apenas para empréstimos de livros para uso pelos professores e estudantes durante as aulas dos Cursos de EJA/EP.

Figura 3 - Biblioteca da EESJ

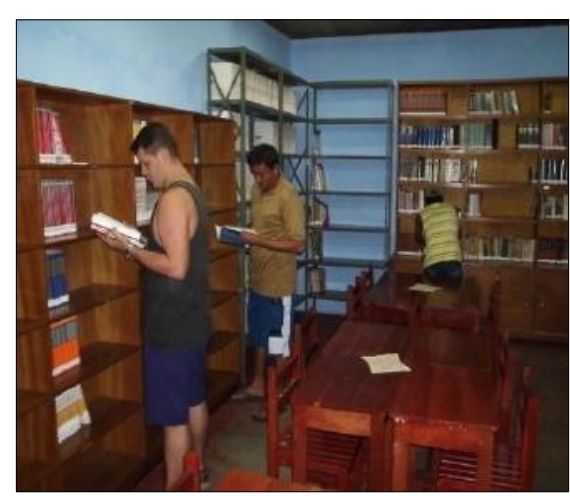

Fonte: EESJ, 2004.
Na Figura 3 observamos uma parte do acervo disponível para leitura e pesquisa na biblioteca da EESJ, em 2004. Também mostra três presos visitando a biblioteca e procurando os livros nos armários.

A visita de presos que já concluíram os cursos de ensino médio era permitido pela diretora da escola, pois eram egressos da escola. Eles também faziam empréstimos de livros para ler nas celas. 


\subsection{Aplicação do Exame de Massa (2006) e Exame Nacional do Ensino Médio (2007)}

O Exame de Massa é uma prova aplicada pela Secretaria de Estado da Educação - SEED, na cidade de Macapá, com a finalidade de jovens adultos, com mais de 18 anos, possam realizar os exames dos cursos da EJA. Os candidatos inscritos no Exame de Massa, se forem aprovados, recebem os seus certificados emitidos pela SEED, que são equivalentes aos certificados dos Cursos de Ensino Fundamental e Médio.

O Exame de Massa da EJA é aplicado para disciplinas de Ciências, Português, História, Matemática, Geografia e Língua Estrangeira em Inglês ou Francês, de acordo com escolha do candidato ao nível de Ensino Fundamental, e Português, Geografia, Biologia, Matemática, História, Física, Literatura, Química, Língua estrangeira - Inglês ou Francês para o Ensino Médio. Este exame é elaborado pela Divisão de Ensino de Jovens e Adultos - DIEJA/SEED, sendo sua inscrição realizada pelos técnicos administrativos e escolar da EESJ.

A equipe de técnicos da DIEJA/SEED era responsável pela aplicação do Exame de Massa aos estudantes da EESJ e aos demais detentos do IAPEN.

Figura 4 - Inscrição no Exame de Massa

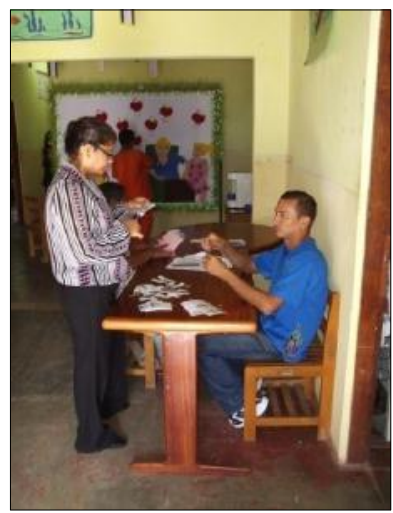

Fonte: EESJ, 2006.

A Figura 4 mostra a educadora penitenciária Maria José Souza Almeida, em 2006, desempenhando a função de secretária escolar.

Ela está recortando as fotografias dos candidatos que desejam realizar inscrição no Exame de Massa, para ser encaminhada pela EESJ à DIEJA/SEED, com o apoio de Raimundo Barros, um detento que trabalhava na escola.

No ano de 2007, dezenove estudantes da EESJ e detentos do IAPEN participaram do Exame Nacional do Ensino Médio - ENEM, organizado pelo Ministério da Educação - INEP/MEC, tendo rendimento escolar na Prova Ob- 
jetiva e Prova de Redação, respectivamente, variando entre 15,87\% a 65,08\% e $25 \%$ a $65 \%$ de acerto das competências avaliadas, conforme a cópia do Boletim Individual do ENEM (EESJ, 2007). Esse dado estatístico revelou a aprendizagem dos estudantes da EESJ, com relação aos cursos ofertados, em 2007, pela modalidade EJA na educação penitenciária, na cidade de Macapá.

\subsection{Participação de estudantes da EESJ em concursos, olimpíada e dos professores na ação social: Criança Sinônimo de Esperança e Amor}

Nos anos letivos de 2006 e 2007, os estudantes da EESJ participaram dos seguintes Concursos e Olimpíada: Concurso de Redação Ler é preciso, com o tema "O melhor lugar do mundo"; Concurso de Redação "Escrevendo a Liberdade" para população carcerária do Brasil, promovidos pelo Instituto ECO, Departamento Nacional Penitenciário - DEPEN e a Ministério da Ciência e Tecnologia - MCTIC, e ainda o Ministério da Educação - MEC.

Nesse período os estudantes da EESJ também participaram da Olimpíada Brasileira de Matemática das Escolas Públicas - OBMEP, cooordenado no Amapá pelo professor Steve Wanderson Calheiros de Araújo do Curso de Graduação em Matemática da Universidade Federal do Amapá.

A inscrição dos candidatos foram realizadas por fichas com os dados dos estudantes da EESJ e detentos do IAPEN, para encaminhar às instituições promotoras dos Concursos Nacionais e da OBMEP. Em 2006, Jean Alex Facundes Rocha e Garibalde José Teodoro, estudantes da EESJ e presos do IAPEN, foram premiados com medalhas de bronze, o que é equivalente ao terceiro lugar da OBMEP ${ }^{3}$.

Em 12 de outubro de 2007, data em que se comemora o dia da criança, os servidores do IAPEN e professores da EESJ promoveram a Ação Social: "Criança Sinônimo de Esperança e Amor" (Figura 5), tendo como participantes as crianças que visitam, constantemente, seus pais e mães que estão cumprindo sentença criminal ou estavam detidos no IAPEN, no caso de homens, ou mulheres custodiadas na Coordenadoria da Penitenciária Feminina - COPEF.

\footnotetext{
${ }^{3}$ Conforme resultado que foi encaminhado via e-mail eletrônico pelo Curso de Matemática da UNIFAP à EESJ, no ano de 2007.
} 
Figura 5 - O Cantinho do Conto

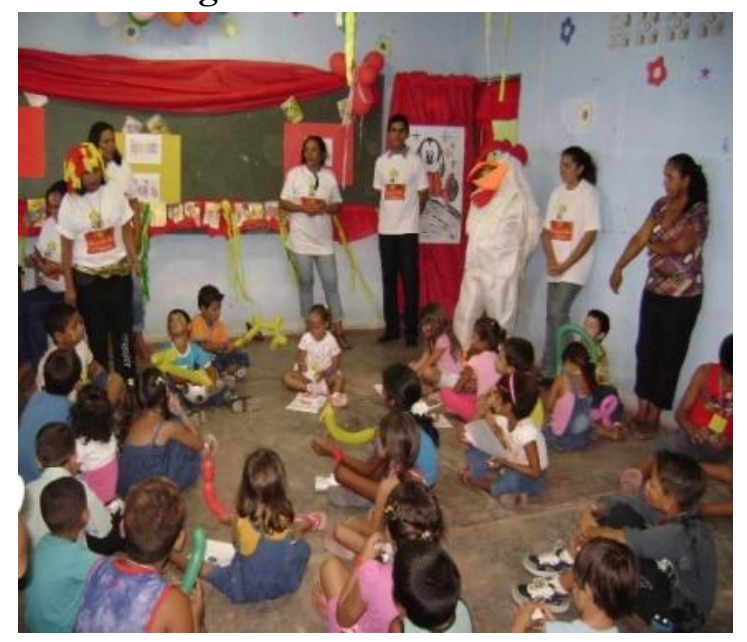

Fonte: (EESJ, 2007).

A programação da ação social contemplou as seguintes atividades recreativas para crianças: Cantinho do Teatro, Cantinho do Conto, Cantinho da Massa, entre outros, com animação de personagens das histórias infantis.

A ação social teve como objetivo acolher as crianças e realizar atividades artísticas e recreativas apropriadas às suas faixas etárias, com o objetivo de promover um espaço prisional dentro da EESJ, mais humano e próximo do mundo da criança, considerando que nas datas de visitas, muitas crianças entram na penitenciária, acompanhadas de seus responsáveis.

\section{CONSIDERAÇÕES FINAIS}

Mesmo com as dificuldades que a EESJ enfrenta no seu cotidiano, como, por exemplo, pouco espaço físico para desenvolver a programação do calendário escolar, ela vem garantindo a assistência educacional no sistema penitenciário amapaense.

Cabe observar que em 2007, a escola ofertava Curso de Ensino Fundamental pela modalidade EJA na educação penitenciária, e também o Curso de Ensino Médio aos adultos presos desde 2004, sendo seu corpo docente, os professores habilitados em Cursos de Licenciaturas e que são servidores públicos do Governo do Estado do Amapá.

Considerando que em 2004, a LEP ainda não determinava como obrigação das Unidades Federadas ofertar o curso de Ensino Médio às pessoas pre- 
sas, constatamos que o Estado do Amapá foi um dos pioneiros a implementar o Ensino Médio à população carcerária no Brasil, pois a gestão escolar e o corpo docente da EESJ assumiram o compromisso com os adultos presos e corpo discente da escola, para que eles pudessem continuar seus estudos após a conclusão do Ensino Fundamental dentro da prisão.

Assim, a EESJ desenvolveu não apenas um papel educacional dentro do restrito espaço destinado à escola. Por outro lado, ela tem um papel social, considerando que os estudantes e detentos participaram de cursos da EJA, projetos e outras ações que ocorreram de 2005 a 2007, a exemplo da inscrição no Vestibular, Ação Social: Criança Sinônimo de Esperança e Amor, além da participação nos Concursos Nacionais e da OBMEP. A programação escolar, além de outros projetos, concursos/olimpíada que os estudantes tiveram acesso nesse período, mostra a visão do corpo docente, técnico e administrativo de fazer com que os adultos presos se sentissem como parte da comunidade escolar amapaense.

É importante dizer que a EESJ poderia realizar outros projetos e ações sociais que colaborem com a integração social. A escola necessita de mais recurso didático e principalmente tecnológico, assim como de apoio de mais parceiros e colaboradores que acreditem na importância de investir na formação escolar da população carcerária.

As atividades educativas, sociais e recreativas contribuíram para o processo de desprisonização de uma parte dos detentos, pois os adultos presos que participaram da programação escolar, tiveram a oportunidade de comunicar-se oralmente por meio da linguagem coloquial em sala de aula, o que equivale a deixar de comunicar-se no espaço escolar pela linguagem local da cultura prisional.

\section{REFERÊNCIAS}

ABREU, A. A. Educação entre grades: um estudo sobre a educação penitenciária no amapá. 2008. Dissertação (Mestrado em Educação) - Universidade Federal de São Carlos, São Carlos, 2008.

ALBERTI, V. Manual de história oral. 3.ed. Rio de Janeiro: FGV, 2005.

ALMEIDA, E. C. G. Prisão penitenciária ou instituição penal: um olhar histórico sobre o sistema carcerário do estado do Amapá e suas transformações. 2006. Monografia (Graduação em História) - Faculdade de Macapá, Macapá, 2006. 
AMAPÁ. Lei no 0692/02. Estabelece as normas de execução penal no Estado do Amapá. Diário Oficial do Estado no 2821, Macapá, 08 de julho de 2002. BRAGA, A. S. C.; SOARES, E. R.; M., S. C. C.; CORRÊA, O. S. Educação entre grades? 2002. Monografia (Graduação em Pedagogia) - Universidade Federal do Amapá, Macapá, 2002

BRASIL. Lei no 3274 de 02 de outubro de 1957. Estabelece as Normas Gerais do Regime Penitenciário e amplia as atribuições da Inspetoria Geral Penitenciária. Diário Oficial da União, Brasília, Seção 1, 3 de outubro de 1957.

Lei no 7.210 de 11 de julho de 1984. Institui a Lei de Execução Penal.

Diário Oficial da União, Brasília, Seção 1, 13 de julho de 1984.

CLEMMER, D. The Prison Community. New York: Holt, Rinehart and Windston, 1960.

CLEMENTE, L.; ALMEIDA, R. R.; PASSOS, L. N. S. (re)socialização de apenados no estado do Amapá: o papel social da escola estadual são josé. De 2005 a 2007. 2008. Monografia (Especialização em Gestão do Trabalho Pedagógico, Direção, Supervisão e Orientação) - Faculdade Internacional de Curitiba. Macapá, 2008.

DIAS, A. S.; PINHEIRO, J. F.; SHERRING, K. D.; SOUZA, L. A. A Educação no Complexo Penitenciário do Estado do Amapá. 1999. Monografia (Graduação em Pedagogia) - Universidade Federal do Amapá, Macapá, 1999.

ESCOLA ESTADUAL SÃO JOSÉ. Cópia da Lei no 0692/02. Estabelece as normas de execução penal do Estado do Amapá. Macapá, 2002. (Arquivo Escolar, EESJ: Pasta de documentos recebidos).

Cópia da Portaria TJAP n ${ }^{0}$ 009/05-VEP. Estabelece a autorização para remissão de pena pelo estudo a condenados sujeitos aos regimes descritos pela Lei Penal e demais Leis Especiais. Macapá, 2005. (Arquivo Escolar: Pasta documentos recebidos).

Ofício $\mathbf{n}^{\circ} \mathbf{0 3} / 06$. Faz solicitação do envio de professores para assistência educacional em nível de $2^{\circ}$ grau. Macapá, 2006. (Arquivo Escolar: Pasta de Ofícios).

. Diretório iconográfico da assistência educacional. Macapá, 20042007. (Arquivo Escolar: Pasta digital criada no computador). 
Cópia de boletim individual de resultados do ENEM. Macapá, 2007. (Arquivo Escolar: Resultado da participação de dezenove estduantes presos no ENEM).

FOUCAULT, M. Vigiar e punir: nascimento da prisão. Trad. de Lígia. M. Pondé Vassalo. Petrópolis: Vozes, 1977.

A verdade e as formas jurídicas. 3.ed. Trad. de Roberto Cabral de Melo Machado e Eduardo Jardim Morais. Rio de Janeiro: Nau, 2005.

GOMES, L. F. (Org.) Constituição Federal, Código Penal, Código de Processo Penal. 8.ed. São Paulo: Revista dos Tribunais, 2006. Vol. 2.

MARCÃO, R. Crise na execução penal III: da assistência jurídica e educacional. 2005. Disponível em: < http://www.direitonet.com.br $>$. Acesso em: 03 mai. 2007.

NUNES, A. A realidade das prisões brasileiras. Recife: Nossa Livraria, 2005.

NUNES, O. A. Relatório sobre a participação no Seminário de Articulação Regional e Consolidação das Diretrizes para a Educação no Sistema Penitenciário Norte e Centro-Oeste. Macapá: SEED/EESJ, 2007.

OLIVEIRA, Z. M. Proposta de ampliação da Escola Estadual São José. Macapá, 21 set. 2007. (Arquivo Escolar: Slide em PowerPoint).

SILVA, C. R. S. O; OLIVEIRA, K. P.; NÓBREGA, L. V. Sistema prisional. A recuperação do preso: utopia ou realidade? 2001. Monografia (Graduação em Direito) - Universidade Federal do Amapá, Macapá, 2001.

THOMPSON, A. F. G. A questão penitenciária. Petrópolis: Vozes, 1976.

UNESCO. Relatório nacional para educação na prisão. Brasília: UNESCO/MJ/ME, 2006.

Resultados do II Seminário Nacional pela Educação em Prisão: Proposições dos Seminários Regionais. Brasília: UNESCO/MJ/ME, 2007. UNIVERSIDADE FEDERAL DO AMAPÁ. Processo Seletivo 2008. Relação dos classificados. Disponível em: < http://www.unifap.br/depseq $>$ Acesso: 08 out. 2008.

VASQUEZ, E. L. Educação matemática penitenciária em ação: um relato de expressão corporal sobre o conceito de família a partir do olhar do aluno-preso. In: CONFERENCIA INTERAMERICANA DE EDUCACIÓN 
MATEMÁTICA. 2007, 12. Anais... Santiago de Querétaro: Edebé México, 2007a. (Cd organizado por E. M. Martinéz e C. A. O. Gamboa).

. Projeto Teia da Desprisonização. Macapá, 2007b. (Arquivo Escolar: Pasta de Projetos).

. Entrevista concedida para Lisete Clemente, Roma Reis de Almeida e Leila Nazaré dos Santos Passos. Macapá, 2007c.

. Uma análise de imagens da destilação de álcool e educação penitenciária contidas em "o prisioneiro da grade de ferro. Auto-retratos". 2007d. Monografia da disciplina História da Qúimica (Mestrado em História da Ciência) - Universidade Católica de São Paulo, São Paulo, 2007d.

Sociedade cativa. Entre cultura escolar e cultura prisional: uma incursão pela ciência penitenciária. 2008. Dissertação (Mestrado em História da Ciência) - Pontifícia Universidade Católica de São Paulo, São Paulo, 2008. 